\title{
Science Implementation of Forecast Mekong for Food and Environmental Security
}

Forecast Mekong is a significant international thrust under the Delta Research and Global Observation Network (DRAGON) of the U.S. Geological Survey (USGS) and was launched in 2009 by the U.S. Department of State and the Foreign Ministers of Cambodia, Laos, Thailand, and Vietnam under U.S. Department of State Secretary Hillary R. Clinton's Lower Mekong Initiative to enhance U.S. engagement with countries of the Lower Mekong River Basin (fig. 1) in the areas of environment, health, education, and infrastructure. Since 2009, the USGS has worked closely with the U.S. Department of State; personnel from Cambodia, Laos, Thailand, and Vietnam; nongovernmental organizations; and academia to collect and use research and data from the Lower Mekong River Basin to provide hands-on results that will help decisionmakers in future planning and design for restoration, conservation, and management efforts in the Lower Mekong River Basin.

In 2012 Forecast Mekong is highlighting the increasing cooperation between the United States and Lower Mekong River Basin countries in the areas of food and environmental security. Under the DRAGON, Forecast Mekong continues work in interactive data integration, modeling, and visualization system by initiating three-dimensional (3-D) bathymetry and river flow data along with a pilot study of fish distribution, population, and migratory patterns in the Lower Mekong River Basin. When fully developed by the USGS, in partnership with local governments and universities throughout the Mekong River region, Forecast Mekong will provide valuable planning tools to visualize the consequences of climate change and river management.

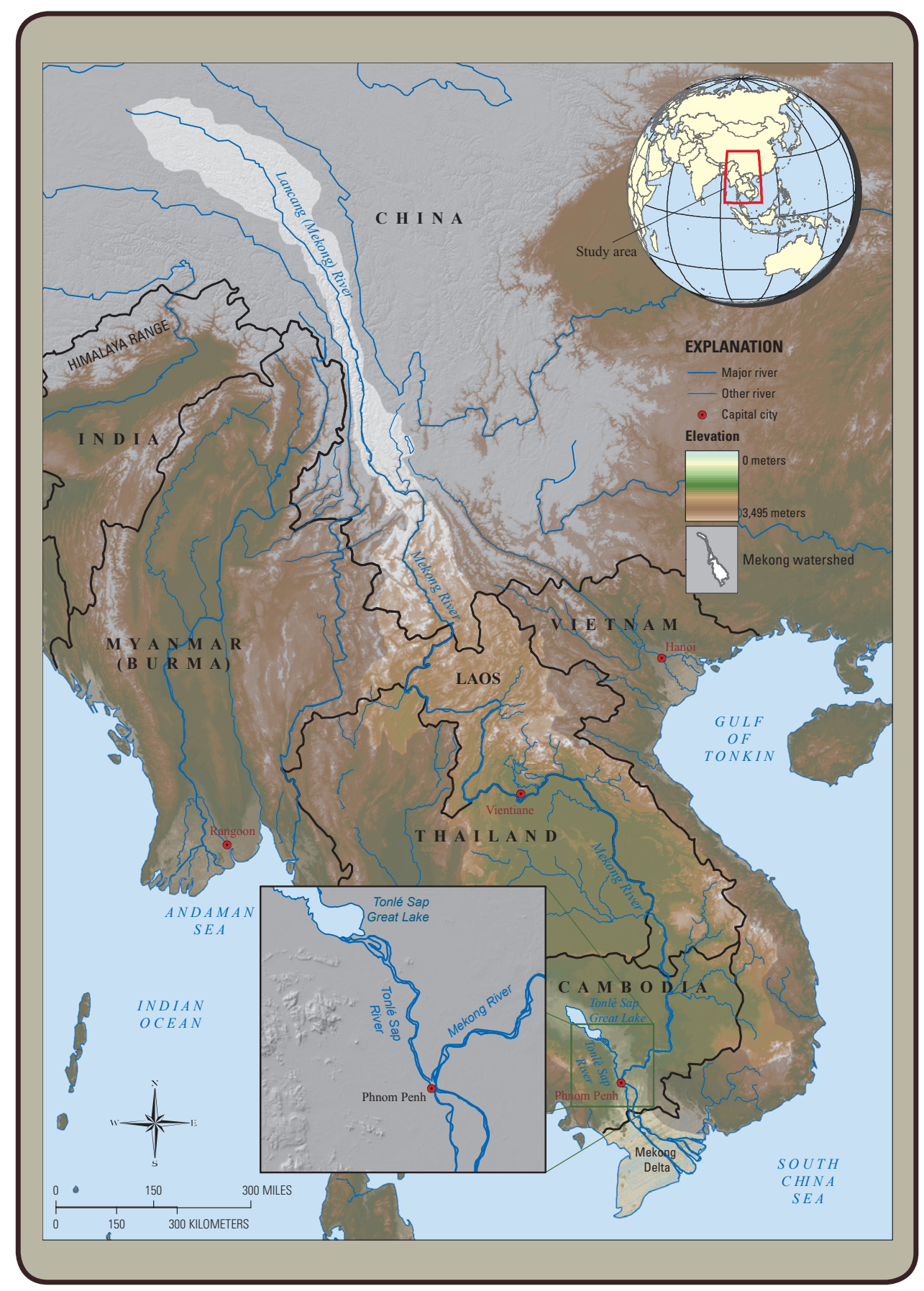

Figure 1. Map of the Mekong River Basin. 


\section{Creating 3-D Bathymetry and Flow Visualization}

In 2012 the USGS is building a graphic visualization tool (GVT) (fig. 2) of bathymetry and hydrology for selected reaches of the Mekong River upstream and downstream from the confluence of the Tonlé Sap River near Phnom Penh, Cambodia. The GVT will demonstrate the potential for use of visualization tools at proposed dam sites on the main stem of the Mekong River to initiate the development of baseline data needed to better understand the potential effects of hydropower and irrigation dams on the hydrology and ecology of the Mekong River and Delta.

USGS field crews visited the Mekong River near Phnom Penh in the early spring of 2012 to collect real-time bathymetric parameters and flow discharge in the Mekong River upstream and downstream from the confluence of the
Tonlé Sap River to characterize flow patterns and channel geometry during the dry season in the region. In addition, the USGS collected 3-D channel geometry and river velocity data at a proposed hydropower dam site upstream from Phnom Penh. Working closely with personnel of the Mekong River Commission, the USGS provided hands-on training on multibeam sonar and acoustic Doppler current profiler instrumentation with the intent to transfer this knowledge and ability to the region for construction of a complete bathymetric map of the Lower Mekong River and appropriate tributaries.

The overall objective of the 2012 bathymetry project is to provide all of the visualization and modeling code with annotation and live demonstrations to show proof of concept and to stimulate data and idea exchange for improved product development. The 2012 GVT incorporates 3-D animation of

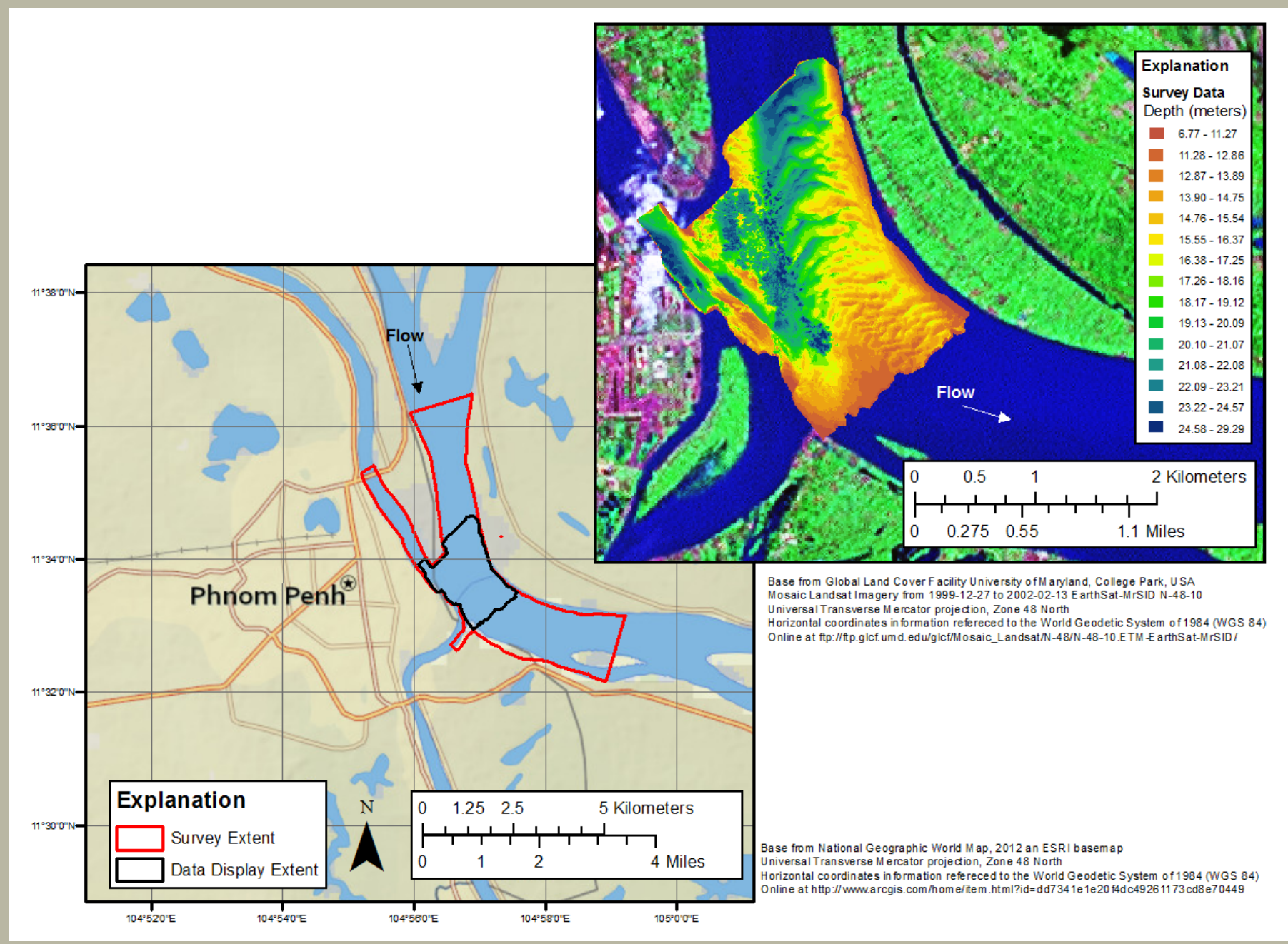

Figure 2. Example of three-dimensional bathymetric map results for a survey by the U.S. Geological Survey and the Mekong River Commission of the Mekong River upstream and downstream from the Tonlé Sap River confluence near Phnom Penh, Cambodia. 
actual river flow velocity and bathymetric regimes to illustrate examples of baseline data needed for the Mekong River to assess overall food security of the region from projected alterations of fisheries production and migration, agricultural systems, and other important ecosystem services. The 2012 project includes the following tasks:

- collect 3-D bathymetry, velocity, and streamflow data for select reaches of the Mekong and Tonlé Sap Rivers upstream and downstream from Phnom Penh;

- construct a computer animation for the Mekong and Tonlé Sap Rivers from bathymetry, velocity, and streamflow data collected in 2012 by using existing USGS digital elevation, hydrologic, political, and ecological boundaries and layers; and

- enhance an existing graphical user interface for model functions and parameters relating to streamflow, fisheries, and agricultural changes in different viewing formats.

\section{Pilot Fish Study Begins Addressing the Science Behind Food Security}

The Lower Mekong River Basin nations have varying capacity for available fisheries research. The nations of Thailand and Vietnam have collected the most fisheries data along their respective reaches of the Mekong River in recent years and currently have the most available staff with which to continue collecting data; the other nations have less available data and scientific staff. It should be recognized that one cannot simply refer to the research and capacity in a given nation because the fisheries scientists in each nation come from diverse employers, including government, universities, and nongovernmental organizations.

The ultimate goal of USGS work in the region with respect to fish populations is to establish and maintain the Mekong Fish Monitoring Network (fig. 3); however, there are many challenges for such a network. The four Lower Mekong River Basin nations are in critical need of a better understanding of their fisheries, but because of economic constraints, participation in fish monitoring may be complicated. For the USGS and cooperative partners, the 2012 pilot fish study, analysis, and capacity building to stress the importance of food security provide a beginning to addressing this paramount need. The USGS pilot fish study will build capacity among local nations so that eventually local scientists can lead their own monitoring and analysis efforts.

\section{Knowledge Transfer and Capacity Building}

The USGS continues to build capacity, databases, and networks to help the Mekong River Commission and the four Lower Mekong River Basin nations in geospatial technology. The following two tasks will continue to be developed in 2012:

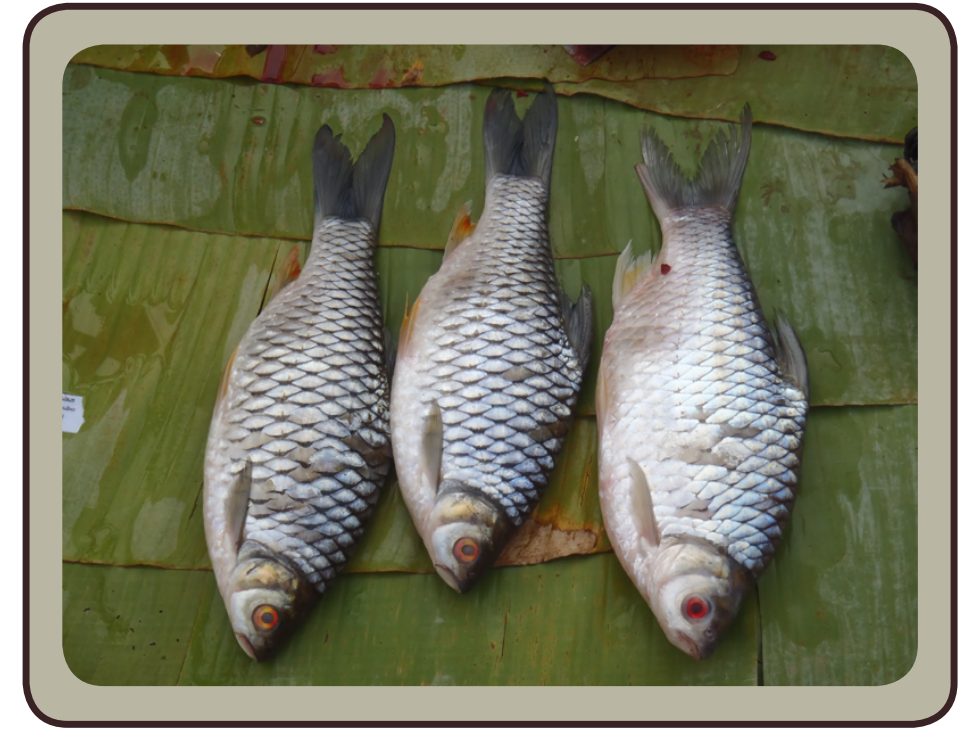

Figure 3. Fish, a critical component of human diets in and around the Lower Mekong River Basin, are shown here offered for sale at the morning market in Luang Prabang, Laos (species shown is Henicorhynchus siamensis). Despite the importance of fish in the area, only limited information about the fish community is available to managers and decisionmakers. Additional study and analysis of the fish community are needed to better characterize the status and trends of this important resource, a goal of the recently established Mekong Fish Monitoring Network.

- Community-Based Salinity Monitoring Project: Can Tho University has selected participants to collect water samples in Bac Lieu Province in the Mekong River Delta of Vietnam. The participants have received the sampling equipment and have been trained to take salinity samples and transmit the results. In 2012 the USGS will increase data collection so that it occurs at regular intervals (that is, daily) and so that the data can be transmitted in real-time for display on a Web site.

- Historical JOG Maps: The USGS received 126 digitally scanned, historical military maps in February 2012. The USGS has completed the georectification of the maps and will begin making them available to the scientific community and the general public through a Web mapping application on the USGS Forecast Mekong Web site in the summer of 2012.

\section{World Wide Web Remote Sensing and Data Sharing for the Mekong Region}

In 2012, monthly cloud-filtered and monthly averaged, moderate resolution imaging spectroradiometer (MODIS) satellite images will continue to be developed to provide a bird's eye view of the Lower Mekong River Basin Publicly Available Web Mapping 
Application for Cloud-Filtered MODIS. MODIS scenes and monthly MODIS-based greenness/wetness indices are continuing to be developed as the scenes are imaged. The USGS is working with the National Aeronautics and Space Administration to develop improved algorithms to process MODIS data for flood monitoring and also to automate the process of continuously serving the new greenness/wetness indices on the Web each month. The MODIS images were used to develop baselines of conditions for the widely used normalized difference vegetation index (NDVI). Departures from baseline conditions were calculated each month from 2002 to 2010 and can be used to monitor changes in growth patterns of plants and flooding or drought extent. USGS scientists are automating the image acquisition and processing so that new monthly NDVI data will be continuously available on the Forecast Mekong Web site.

The Forecast Mekong Web site (http://deltas.usgs.gov/ $\mathrm{fm} /$ ) provides a publicly available Web interface to serve data, reports, and scientific visualization products. The Web site includes an interactive Web mapping application to view and download regional downscaled climate data for the Mekong Basin to aid in climate change research in Southeast Asia.

Forecast Mekong continues to provide a forum for regional partners, scientists, and engineers in the Lower Mekong River Basin countries to share data and support local research efforts and elevate knowledge about the vital importance of the Mekong River and Delta in maintaining food security and livelihoods in the region. DRAGON and Forecast Mekong will lead to more informed decisions about how to make the Mekong and Mississippi River Deltas resilient and sustainable in the face of climate change, economic stresses, and other impacts.

\section{-D. Phil Turnipseed (P.E.)}

\section{For more information, contact}

Director, National Wetlands Research Center U.S. Geological Survey 700 Cajundome Blvd. Lafayette, LA 70506

337-266-8500

nwrcdirector@usgs.gov

http://www.nwrc.usgs.gov/

Publishing support provided by Lafayette Publishing Service Center

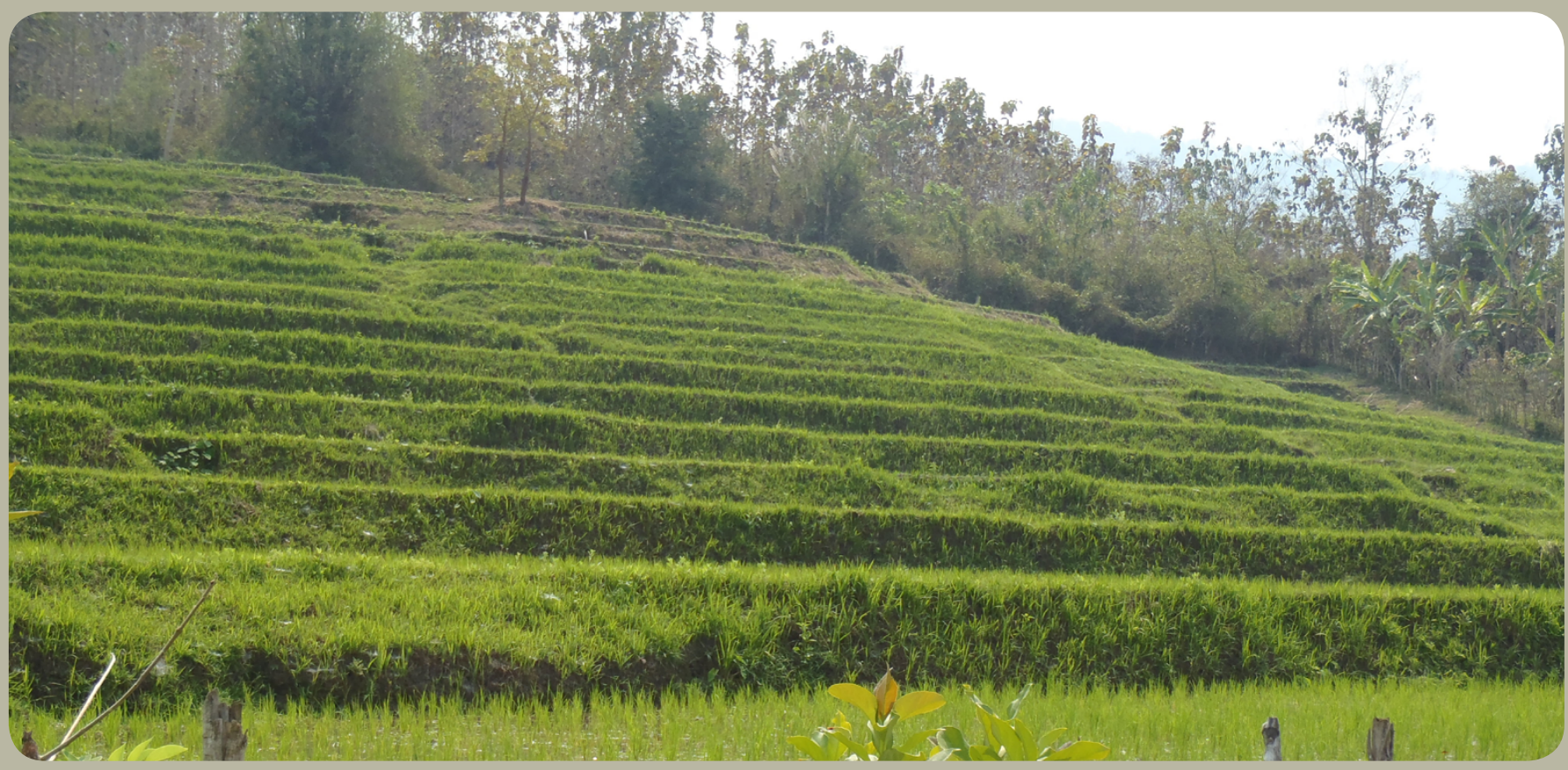

